\title{
A machine learning logistic classifier approach for identifying the determinants of Under-5 child morbidity in Bangladesh
}

\author{
Md. Injamul Haq Methun ${ }^{\mathrm{a}, *}$, Anowarul Kabir ${ }^{\mathrm{a}}$, Saiful Islam ${ }^{\mathrm{b}}$, Md. Ismail Hossain ${ }^{\mathrm{c}}$, \\ Md Abud Darda ${ }^{\mathrm{d}}$
}

${ }^{a}$ Department of Statistics, Tejgaon College, Dhaka, Bangladesh

${ }^{\mathrm{b}}$ Shibalaya Sadar Uddin Degree College, Manikganj, Bangladesh

c Jagannath University, Dhaka, Bangladesh

${ }^{\mathrm{d}}$ National University, Gazipur, Bangladesh

\section{A R T I C L E I N F O}

\section{Keywords:}

Machine learning

Supervised learning

Under 5 morbidity

Child health

\begin{abstract}
A B S T R A C T
Background: Numerous biological, maternal, family, and socio-economic factors are regarded as influencers of child morbidity. The current study focuses on determining the factors that regulate the incidence of preventable outbreaks of disease or symptoms among under 5 children in Bangladesh.

Methods: This study used data from the most recent nationally representable cross-sectional Bangladesh Multiple Indicator Cluster Survey (MICS) data which is conducted in 2019. In this study, the Machine Learning algorithm of Logistic Classifier has been applied to the information of 23,099 children age below 5 years.

Result: In general, younger children, male children (OR $=1.087,95 \%$ CI (1.012-1.167)), and children of the young mother are more likely to suffer from the disease than their counterparts. Children belonging to the household which have improved toilet (OR $=0.88,95 \% \mathrm{CI}(0.79-0.98)$ ) and use salt that contains above 15 PPM (OR $=0.926,95 \%$ CI (0.846-1.014)) are faced a lower risk of illness than those households which did not have improved toilet and used salt that contain lower than the 15 PPM iodine.

Conclusion: Besides those household factors wealth quintile, household size, materials used for hand wash were found with a significant impact on morbidity. However, it is observed that water treatment practice alone had no impact on child morbidity. Accelerated initiatives that encourage access to and use of hygienic sanitation, the use of salt with adequate iodine, and a healthier household climate can be effective in the reduction of childhood morbidity in Bangladesh.
\end{abstract}

\section{Introduction}

The under-five child mortality rate of Bangladesh, 90 death per 1000 live birth, is the third highest in South-Asia, while the south-Asia region, along with Sub-African countries, accounted for $80 \%$ of 5.2 million preventable under-five child death. ${ }^{1}$ Many of these under-five deaths have occurred because of preventable causes, such as pneumonia, diarrhea, acute respiratory infection, and malaria. ${ }^{2}$ These preventable causes account for around $33 \%$ of children worldwide under-five mortality. ${ }^{2}$ In 2017, Bangladesh accounted for 7501 under-five child death due to diarrhea and 13,656 under five lives for an acute respiratory infection. ${ }^{3}$ Applying Johns Hopkins University's Live Saved Tools (LiST), in January 2020, it is forecasted that higher than $1,00,000$ children under the age of five will die from pneumonia over the next decade in Bangladesh. ${ }^{4}$ This amount will significantly increase if added with the millions of child death for other conventional forms of childhood morbidity. ${ }^{5}$ Moreover, the disruption of routine child health services as the effect of COVID-19 can alarmingly increase the forecasted under-five death. ${ }^{6}$ Only a boosting effort to fight pneumonia could avert nearly $1,400,000$ child death. ${ }^{4}$ Causality is not only the consequence of morbidity, but it also impedes regular physical progress during childhood, leading to a higher rate of inadequate nutrition. ${ }^{5,7}$ Therefore, it is high time to boost multiple initiatives to prevent an enormous amount of under-five child death and put acceleration to achieve the SDG target of ending preventable deaths of under 5 children to reduce child mortality to below 25 per thousand live births. ${ }^{8}$

It is essential to determine the determinants of child morbidity to formulate important boosting multiple initiatives against child

\footnotetext{
* Corresponding author. Department of Statistics, Tejgaon College, Dhaka, 1215, Bangladesh.

E-mail address: imethuns7@gmail.com (Md.I.H. Methun).
} 
morbidity. In the least income countries, various factors linked with the environment, which consists of children themselves, parents, and the household setting in which they grew up, influence the exposure and reaction of morbidity. ${ }^{5}$ Previous evidence indicates that younger and female children are more likely to endure morbidity., 10 Stunting, wasting, and underweighted children have a severer risk of death due to superior forms of morbidity such as diarrhea, pneumonia, ARI, etc. ${ }^{11}$ Parental education and economic status remain well-known crucial critical factors of child morbidity. ${ }^{5,12,13}$ Higher parental academic attainment can contribute to healthier hygiene habits such as washing hands with soaps after toilet use, decreasing children's exposure to waterborne disease. ${ }^{12}$ There has been a significant connection between childhood morbidity status and better toilet facilities, water supply sources, and water treatment practices. ${ }^{5}$

Machine learning algorithms detect useful patterns from previous experience of large and complex data set using a variety of statistical methods. ${ }^{14}$ Machine learning algorithms have been used in many different fields including disease modeling. ${ }^{15}$ Machine learning algorithms have been used to predict a variety of diseases such as diabetes, hypertension, comorbidity, ${ }^{16}$ cancer, ${ }^{16}$ asthma, ${ }^{17}$ cardiac disease, ${ }^{18}$ Parkinson, ${ }^{19}$ etc. In the past, machine learning models were widely used for predictive purposes but recently these techniques have been widely applied for finding factors and correlation among important factors of child mortality. ${ }^{20}$

This present study explores socio-economic factors that affect underfive child morbidity in Bangladesh using the machine learning logistic classifier approach. Several studies have until now been undertaken on the determinants of child morbidity. ${ }^{5,9,10,12,21,22}$ Those studies have been performed on old data sets when under-five morbidity was declining sharply. Nevertheless, in the present circumstances, the rate of decline is becoming moderate day by day. ${ }^{23}$ Therefore, we need to consider such a type of study from a distinct point of view. Mother perceived a more extensive role in children's upbringing. Therefore, this study takes the mother's quality of life with significant importance along with their education and other biological conditions. Such an approach is never taken into consideration before. Examining childhood morbidity's driving forces more interactively could provide insights into identifying priority health interventions both within well beyond the current healthcare system. Furthermore, fundamental results addressed in the context of Bangladesh's national development plan and the perception of massive health care programs could lead directly and indirectly to a decrease in childhood morbidity and mortality.

\section{Materials and methods}

\subsection{Data source}

This study is based on secondary data. In the cross-sectional analysis, data from a nationally representative household sample, Bangladesh Multiple Indicator Cluster Survey (MICS) 2019 has been examined. The Bangladesh Multiple Indicator Cluster Survey (MICS) was carried out in 2019 by the Bangladesh Bureau of Statistics (BBS) in collaboration with UNICEF Bangladesh, as a part of the Global MICS program. Using a twostage, stratified cluster sampling technique, the MICS data are collected. The sampling technique, design of the survey, tools, measuring method, the validity of information, reliability are discussed in the survey report. ${ }^{24}$ As per the norm of MICS procedures, before conducting the survey, consent was gathered from all potential respondents. The MICS Dataset is freely accessible, but as part of the protocol, mailed consent was also obtained. The research presented here was confined to mothers or caretakers of children under five years of age. The study omitted contradictory, irregular, or uncommon, and incomplete observations. Finally, the study contained a total of 23,099 sample observations.

\subsection{Outcome variable}

The choice of the outcome variable is made in a way that allows determining whether, in a given time period, children born in the last 5 years have encountered a health problem. Both findings were based on a maternal statement on infectious disease outcomes like ARI (cough, fast breathing, blocked or runny nose), diarrhea, or fever in the past 2 weeks. It is difficult to integrate diseases into one variable since all diseases do not carry the same risk factors. One way to deal with the situation is to classify the data into single diseases and their different combinations as well. However, modeling variables with a large number of categories added to the calculation of parameters more complexity and ambiguity. This research, therefore, considered a way in which the variable of morbidity is divided into two categories: those experiencing 'no condition' and 'at least one condition'.

\subsection{Independent variables}

A set of 19 variables were taken for the analysis. These variables included social, demographic, medical, economic, and mother's psychology (Life satisfaction) related factors. The list of independent variables and their measures are in Table 1.

\subsection{Analytical tools}

The sample sociodemographic characteristics were described using unweighted percentages. As the model becomes more and more complex (more dimensional), it uses training data more, and the training error decreases i.e., the model overfit the training data and will typically generalize poorly. ${ }^{25}$ Since, in these study psychological, demographic, and social variables were included in the model and the model becomes complex. Therefore, there is a high possibility that the simple logistic regression model can become overfitted. Therefore, the Supervised learning procedure Logistic Classifier (Logistic Regression) is used in this study to find out the determinants of childhood morbidity. The forward feature selection procedure has done using the area under the curve (AUC) value. Model efficiency evaluated using AUC and confusion matrix.

The analysis procedure is carried on using the $\mathrm{R}$ programming

Table 1

Description of Independent variables.

\begin{tabular}{ll}
\hline Variables & Measures \\
\hline Sex of Child & Female, male \\
Ethnicity & Bengali, Other \\
Child's age in month & $1-11,12-23,24-35,36-47,48-59$ \\
Birth intervals & First birth, $<2$ years, 2 years, 3 years, 4+ years \\
Birth order & $1,2-3,4-6,7+$ \\
Overweight & Yes, No \\
Mother or primary caretaker's & Higher secondary+, Secondary, Primary, Pre- \\
education & primary or none \\
Mother's age at birth & $<20,20-34,35+$ \\
Mother or primary caretaker's & $1-6,7-10$ \\
$\quad$ life satisfaction in ladder & \\
Residence & Rural, Urban \\
Division & Barisal, Chattogram, Dhaka, Khulna, \\
& Mymensingh, Rajshahi, Rangpur and Sylhet \\
Wealth index of the household & Poorest, second, middle, fourth and richest \\
Salt iodization test outcome & Salt not tested, salt tested: 0 ppm, salt tested: \\
& below 15 ppm, salt tested: above 15 ppm \\
Sex of household head & Female, Male \\
Education level of household & Pre-primary or none or Don't know, Primary, \\
head & Secondary, Higher Secondary or Higher \\
Materials used for handwash & No materials/ASH/Mud/Sand, Bar/Liquid soap/ \\
& Detergent \\
Treat water to make safer for & Yes, No \\
drinking & Improved, not improved \\
Type of toilet & $1-4$, more than 5 \\
Household Size & \\
\hline & \\
&
\end{tabular}




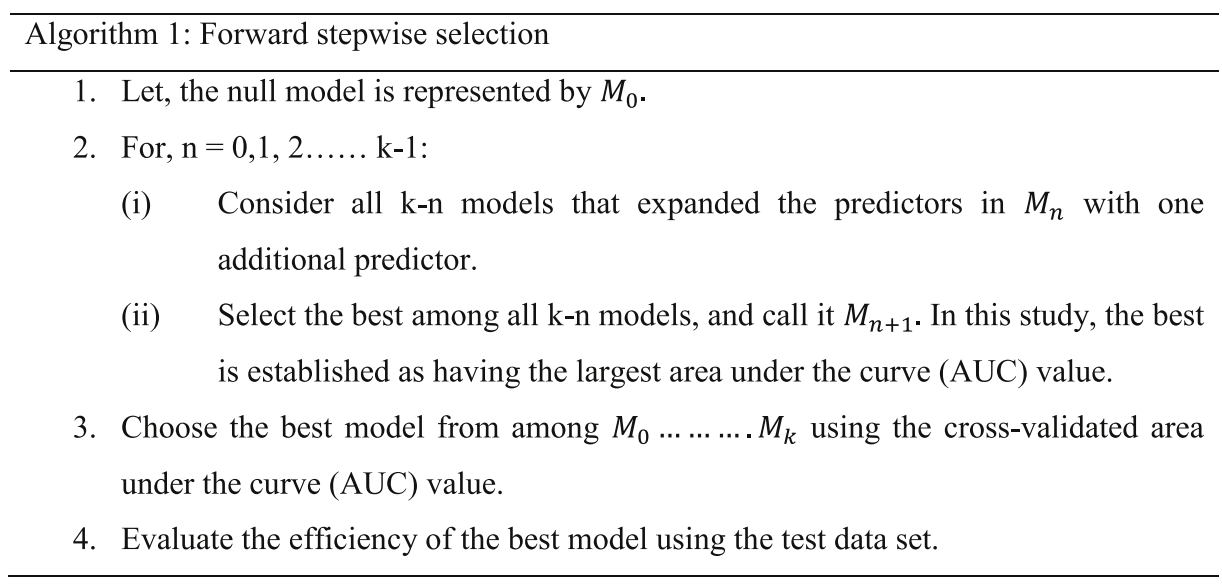

software. While for fitting logistic model applying machine learning approach 'caret' package has been used.

\subsection{Analysis procedure}

At first, the whole data set is divided into two parts one is training and the other is test set.

For rich-data situations, the best approach is to randomly divide the whole data set into three parts: a training set, a validation set, and a test set. The model is fitted using training set data, the validation set is used to estimate the prediction error for the model selection, and the test data set for the assessment of generalization error of the final chosen model. ${ }^{25}$ Since the study data is insufficient, the whole data set is divided into only two parts: training and test set. Then 5 -fold cross-validation is used in the training set. In other words, the training data set was divided into 5 subsets followed by an iterative process of combining 4 folds used for fitting the model, and the remaining fold was used for estimating the prediction error for the model selection.

The larger test data set demonstrated the error estimate more accurately. Since our data is not sufficient to take a larger test. Therefore, $30 \%$ of the original data set randomly is taken as the test set. The remaining $70 \%$ was used as a training data set. Since all independent variables are categorical, they are converted into dummy variables. Dummy variables that had variance near zero had been either excluded from the study or merged with other dummy variables based on their importance on interpretation. After this transformation finally, 51 dummy variables were included in the analysis. Then the analysis proceeded with the forward selection procedure.

The area under the receiver curve (AUC) is used as the model fit index for the forward selection approach since it is recognized as an index for reporting the trade-off between fitting (likelihood) and parsimony (number of the parameter) of the model. AUC values for the forward selection are shown in Fig. 1. The figure indicates that to fit the best model, we should include 28 feature (independent) variables since adding the 28th feature in the model the AUC value becomes the maximum. ${ }^{26}$ Two additional features are included in the model for the convenience of the interpretation. Therefore, in the final model 30 features have been included. The logistic classifier procedure is presented in Algorithm 1.

Algorithm 1. Forward stepwise selection

\section{Results}

\subsection{Characteristics of the children}

Table 2 shows that $27.48 \%$ of children in Bangladesh experienced at least one episode of ill health two weeks before the survey. The number of males $(48.27 \%)$ and female children $(52.73 \%)$ is almost equal. Only $2.27 \%$ of the child are from non-Bengali ethnic backgrounds.

Table 2 also revealed a similar age distribution among the child over the age of 1-59 months. Among all the children, slightly more than one-

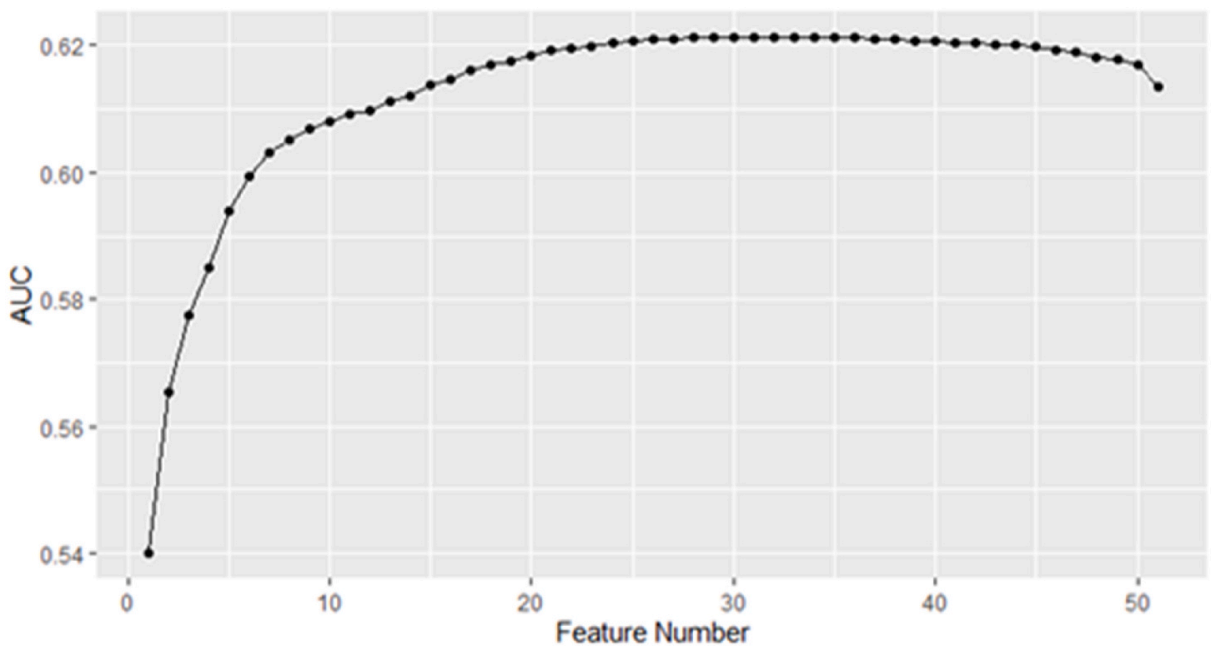

Fig. 1. AUC value for different number of independent variables included in the model. 
Table 2

Characteristics of child $(\mathrm{N}=23,099)$.

\begin{tabular}{|c|c|c|}
\hline Characteristics & Frequency & Percentage (\%) \\
\hline \multicolumn{3}{|l|}{ Sex of Child } \\
\hline Female & 11,149 & 48.27 \\
\hline Male & 11,950 & 51.73 \\
\hline \multicolumn{3}{|l|}{ Ethnicity } \\
\hline Bengali & 22,581 & 97.76 \\
\hline Other & 518 & 2.24 \\
\hline \multicolumn{3}{|l|}{ Morbidity } \\
\hline Yes & 16,751 & 72.52 \\
\hline No & 6348 & 27.48 \\
\hline \multicolumn{3}{|c|}{ Child's age in month } \\
\hline $1-11$ & 4547 & 19.68 \\
\hline $12-23$ & 4514 & 19.54 \\
\hline 24-35 & 4596 & 19.9 \\
\hline $36-47$ & 4790 & 20.74 \\
\hline $48-59$ & 4652 & 20.14 \\
\hline \multicolumn{3}{|l|}{ Birth intervals } \\
\hline First birth & 8160 & 35.33 \\
\hline$<2$ years & 1223 & 5.29 \\
\hline 2 years & 2033 & 8.8 \\
\hline 3 years & 2107 & 9.12 \\
\hline $4+$ years & 9064 & 39.24 \\
\hline NA & 512 & 2.22 \\
\hline \multicolumn{3}{|l|}{ Birth order } \\
\hline 1 & 8116 & 35.14 \\
\hline $2-3$ & 11,860 & 51.34 \\
\hline $4-6$ & 2448 & 10.6 \\
\hline $7+$ & 163 & 0.71 \\
\hline NA & 512 & 2.22 \\
\hline \multicolumn{3}{|l|}{ Overweight } \\
\hline Yes & 1025 & 4.44 \\
\hline No & 22,074 & 95.56 \\
\hline Total & 23,099 & \\
\hline
\end{tabular}

Table 3

Percentage distribution of maternal characteristics of the children.

\begin{tabular}{lll}
\hline Characteristics & Frequency & Percentage (\%) \\
\hline Mother or primary caretaker's education & \\
Higher secondary + & 3586 & 15.52 \\
Pre-primary or none & 2594 & 11.23 \\
Primary & 5563 & 24.08 \\
Secondary & 11,356 & 49.16 \\
Mother's age at birth & & \\
$<20$ & 4896 & 21.2 \\
$20-34$ & 16,299 & 70.56 \\
$35+$ & 1392 & 6.03 \\
NA & 512 & 2.22 \\
Mother or primary caretaker's life satisfaction & \\
$1-6$ & 15,148 & 66.56 \\
$7-10$ & 7610 & 33.44 \\
Total & $\mathbf{2 3 , 0 9 9}$ & $\mathbf{1 0 0}$ \\
\hline
\end{tabular}

third are the first child of their parents. Two-fifth child's preceding birth interval is more than four years, whereas only $5 \%$ of the child's preceding birth interval is less than two years. More than one-half of the child is either the second or third child of their parent. Around $11 \%$ of the child's birth order is four or higher, and $4.4 \%$ of the child have overweight.

\subsection{Maternal characteristics}

Results of Table 3 revealed that $11.23 \%$ of the child's mother or primary caretakers have pre-primary or non-education. Approximately one-fourth of the mother or primary caretaker is not passed the primary school. Half of the mothers attain secondary-level education, and the rest have higher secondary or secondary education. Twenty percent of the reported child's birth was exposed to the high-risk character that at delivery mother's age was barely 20 . Whereas the mother of age at delivery was 35 for $6.3 \%$. Only three percent of the mother remain
Table 4

Percentage distribution of household characteristics of under 5 children.

\begin{tabular}{|c|c|c|}
\hline Characteristics & Frequency & Percentage (\%) \\
\hline \multicolumn{3}{|l|}{ Residence } \\
\hline Rural & 18,796 & 81.37 \\
\hline Urban & 4303 & 18.63 \\
\hline \multicolumn{3}{|l|}{ Division } \\
\hline Barisal & 2066 & 8.94 \\
\hline Chattogram & 4804 & 20.8 \\
\hline Dhaka & 4513 & 19.54 \\
\hline Khulna & 3175 & 13.75 \\
\hline Mymensingh & 1389 & 6.01 \\
\hline Rajshahi & 2407 & 10.42 \\
\hline Rangpur & 2769 & 11.99 \\
\hline Sylhet & 1976 & 8.55 \\
\hline \multicolumn{3}{|l|}{ Wealth index of the household } \\
\hline Fourth & 4310 & 18.66 \\
\hline Middle & 4352 & 18.84 \\
\hline Poorest & 5755 & 24.91 \\
\hline Richest & 3844 & 16.64 \\
\hline Second & 4838 & 20.94 \\
\hline \multicolumn{3}{|l|}{ Salt iodization test outcome } \\
\hline Salt not tested & 123 & 0.53 \\
\hline Salt tested: $0 \mathrm{ppm}$ & 5723 & 24.78 \\
\hline Salt tested: below 15 ppm & 4392 & 19.01 \\
\hline Salt tested: above $15 \mathrm{ppm}$ & 12,861 & 55.68 \\
\hline \multicolumn{3}{|l|}{ Sex of household head } \\
\hline Female & 1827 & 7.91 \\
\hline Male & 21,272 & 92.09 \\
\hline \multicolumn{3}{|l|}{ Education level of household head } \\
\hline Pre-primary or none or Don't know & 6936 & 30.02 \\
\hline Primary & 6959 & 30.13 \\
\hline Secondary & 6434 & 27.85 \\
\hline Higher Secondary or Higher & 2770 & 11.99 \\
\hline \multicolumn{3}{|l|}{ Materials used for handwash } \\
\hline No materials/ASH/Mud/Sand & 3551 & 15.37 \\
\hline Bar/Liquid soap/Detergent & 19,548 & 84.63 \\
\hline \multicolumn{3}{|l|}{ Treat water to make it safer for drinking } \\
\hline Yes & 1974 & 8.55 \\
\hline No & 21,125 & 91.45 \\
\hline \multicolumn{3}{|l|}{ Type of toilet } \\
\hline Improved & 19,604 & 84.87 \\
\hline not improved & 3495 & 15.13 \\
\hline \multicolumn{3}{|l|}{ Household Size } \\
\hline $1-4$ & 14,678 & 63.54 \\
\hline more than 5 & 8421 & 36.46 \\
\hline Total & 23,099 & 100 \\
\hline
\end{tabular}

somehow unhappy. One-third of the overall mother's life satisfaction ladder score is high, that is $7-10$.

\subsection{Household characteristics}

Table 4 demonstrate that $80 \%$ of the child from the rural area. Since MICS data are collected as probability proportional to the size of division; therefore, the number of children in the sample data varies across the divisions. Approximately one-fourth of children belong to the poorest household. While the percentage of other wealth quantile range from 18 to $20 \%$. Among all households, only $7.9 \%$ of household sex is female. While $60 \%$ of household head's educational attainment is below $60 \%$. Only $12 \%$ of the total household head able to manage to complete secondary education. The percentage of a small family that is household size is less than 4 comprised $65 \%$.

Table 4 additionally provides a glimpse of the healthy behaviors of the household. It demonstrates that $15 \%$ of households have not improved toilet facilities. Whereas members of 15.3 families hand washing materials are ash or mud or sand or no materials. Almost $9 \%$ of households processed drinking water to make it safer. It is also uncovered that $25 \%$ of households use salt, which contained no iodine; additionally, $20 \%$ of households' salt had below 15 PPM iodine. 


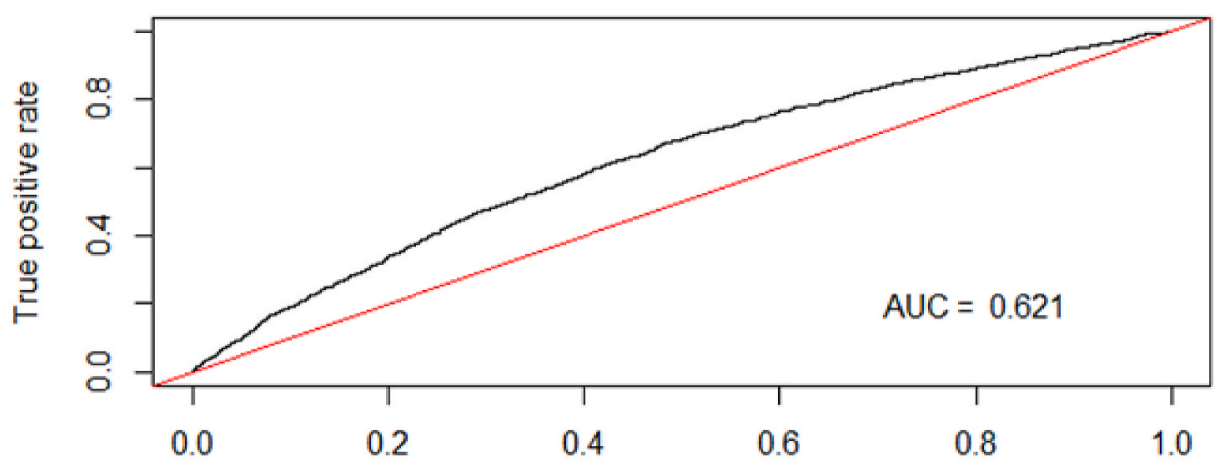

False positive rate

Fig. 2. Area under the curve of the fitted model.

\subsection{Multivariate regression model}

The accuracy of the fitted logistic regression model is 0.7 , which indicates that our fitted model can predict $70 \%$ of the total data point in the test set correctly. Precision and recall of the fitted model are 0.724 and 0.926 , respectively. Whereas the F1 score is 0.812 , and the value of the area under the curve is 0.621 . In Fig. 2, the red line represents "no information classifier," that is, the fitted model had no skill to classify child morbidity. Whereas the black line represents the true positive rate and the false positive rate of the fitted model for different probability or threshold values.

Table 5 showed that male children possessed an $8.7 \%$ more risk to have experienced any health problem than the female. While it is evident that as the child grows older, the incidence of child morbidity becomes less likely. Children of age 23-33 months are almost $10 \%$ (OR $=0.901,95 \% \mathrm{CI}=0.82$ to 0.99 ) less likely to show any health concern than the child of age between 1 and 23 months. The chance of being encountered by any form of morbidity for the child whose age was between 36 and 47 months becomes three-fourths (OR $=0.635,95 \% \mathrm{CI}=$ 0.576 to 0.70 ) compared to the child less than two years. While this chance becomes almost half ( $\mathrm{OR}=0.517,95 \% \mathrm{CI}=0.466$ to 0.574 ) for the age group 48-59 months.

Among all the maternal factors, mother's age at delivery, mother or primary caretaker's education, and life satisfaction score of mother or primary caretaker produced a significant impact on child morbidity. Children whose mother was between 20 and 34-year-old during delivery were $8.9 \%$ (OR $=0.911,95 \% \mathrm{CI}=0.835$ to 0.995 ) less likely to be infected by any form of the disease than the child of same risk delivery, $i$. e., mothers age at delivery was less than 20 years. In contrast, education had no meaningful impact on child morbidity. Mother's secondary or higher secondary education had not any significant impact on child morbidity. Only the child of the mother who gained primary education was a $10 \%$ higher chance to get morbidity than the mother's child had no institutional education attainment. This result may arise from the fact that a $2.2 \%$ mother whose academic attainment remained unknown was included in the reference category. While a mother's life satisfaction improved child morbidity status. Children of highly satisfied mothers or primary caretakers remained $15.8 \%$ less likely to have any form of morbidity than the child of a less satisfied mother or primary caretaker.

Among the household character division, wealth quantile and household size exhibited a significant effect. Children of a family consist of less than four members were $16.4 \%(\mathrm{OR}=1.164,95 \% \mathrm{CI}=1.077$ to 1.259) more risk of conducted any one health problem than the child of a family consists of more than 4 members. Household head's education also documented an impact on child morbidity, which is similar to the mother's education. Whereas the wealthiest family's child was $14.4 \%$ (OR $=0.846,95 \% \mathrm{CI}=0.738$ to 0.97 ) less likely to experience any form of morbidity than the child of a poor family's child.
Children of the household with improved toilet facility were in onetenth (OR $=0.88,95 \% \mathrm{CI}=0.9$. To 0.98$)$ less risk than the household that had not improved toilet facility. The household in which members use unhygienic materials to wash their hands was possessed $18.2 \%$ (OR $=0.818,95 \% \mathrm{CI}=0.679$ to 0.988 ) more risk to their child being infected with the disease than the family used hygienic hand cleaning materials. Finally, the child of the household that consumed salt that contained above 15 PPM salt was $7.4 \%$ less likely to experience any form of morbidity than the child of the household who consumed salt with 0 PPM iodine.

\section{Discussion and conclusion}

Among the typical type of childhood morbidity that led to most child death globally, diarrhea, ARI with their associated symptoms such as fever, cough, and difficulty in breathing are the most common. ${ }^{21,22}$ Every year, $45.7 \%$ of children suffer from these conditions in Bangladesh alone, ${ }^{3}$ although about a third of these children are predicted to die each year because of these conditions. This investigation developed with the specific mandate of determining the factors linked to childhood morbidity in the country. The information can be used for programming and planning purposes by policymakers, development partners, and other related institutions. Logistic regression model applying machine learning approach is fitted on Multiple Indicator Cluster Survey (MICS) 2019 data to identify the factors that can regulate child morbidity. The fitted model can correctly identify $70 \%$ of the cases.

This study's findings demonstrate that various biological factors of child and socio-economic factors produce a significant impact on child morbidity. The findings of this study indicate that age has a substantial impact on the prevalence of morbidity, which is consistent with the findings of previous investigations in Bangladesh and elsewhere. ${ }^{3,24}$ This study revealed that male children are more prone to morbidity compared to female children. A study in Bangladesh ${ }^{10}$ using the BDHS-2014 result also showed that the prevalence of morbidity among male children is higher than that of female children. Other studies in India $^{27}$ and Ethiopia ${ }^{28}$ also depict similar findings. In this study, it is discovered that underweight child is more likely to exhibit the symptoms of morbidity than the overweight. However, Hondru et al. (2019) also showed that child's under nutritional status increased the likelihood of a child's illness. ${ }^{29}$

It is also observed that the incidence of childhood disease varies with maternal education and maternal age at delivery. The findings of this study are also coherent to the finding of a meta-analysis and systematic review $^{30}$ and a cohort analysis ${ }^{27}$ in India. In a pooled analysis of 12 Latin American countries, Hatt and Waters also found that the mother's education and age of delivery significantly affected child morbidity. ${ }^{12}$ Children of very risk delivery always are more likely to develop a childhood disease, which is also consistent with the findings of a 
Table 5

The Logistic Regression model for child morbidity.

\begin{tabular}{|c|c|c|c|c|}
\hline \multirow[t]{2}{*}{ Variables and levels } & \multirow[t]{2}{*}{$\begin{array}{l}\text { Odds Ratio } \\
{[\exp (\beta)]}\end{array}$} & \multicolumn{2}{|c|}{$\begin{array}{l}\text { Confidence } \\
\text { interval }\end{array}$} & \multirow[t]{2}{*}{ P-value } \\
\hline & & $2.5 \%$ & $97.5 \%$ & \\
\hline Intercept & 0.338 & 0.255 & 0.446 & $0.00 * * *$ \\
\hline \multicolumn{5}{|l|}{ Division } \\
\hline Rajshahi (Reference) & 1.00 & & & \\
\hline Chattogram & 0.971 & 0.867 & 1.088 & 0.61 \\
\hline Dhaka & 0.642 & 0.570 & 0.722 & $0.00 * * *$ \\
\hline Khulna & 0.948 & 0.838 & 1.072 & 0.40 \\
\hline Mymensingh & 0.915 & 0.776 & 1.076 & 0.29 \\
\hline Rangpur & 0.651 & 0.569 & 0.744 & $0.00^{* * *}$ \\
\hline Sylhet & 0.600 & 0.512 & 0.703 & $0.00 * * *$ \\
\hline \multicolumn{5}{|l|}{ Sex } \\
\hline Female (Reference) & 1.00 & & & \\
\hline Male & 1.087 & 1.012 & 1.167 & $0.02^{* *}$ \\
\hline \multicolumn{5}{|l|}{ Wealth index of the household } \\
\hline Poor (Reference) & 1.00 & & & \\
\hline Middle & 0.998 & 0.901 & 1.105 & 0.97 \\
\hline Fourth & 1.003 & 0.897 & 1.120 & 0.96 \\
\hline Richest & 0.846 & 0.738 & 0.970 & $0.02 * *$ \\
\hline \multicolumn{5}{|c|}{ Mother or primary caretaker's education } \\
\hline $\begin{array}{l}\text { Pre-primary or none } \\
\text { (Reference) }\end{array}$ & 1.00 & & & \\
\hline Primary & 1.132 & 0.983 & 1.305 & $0.09 *$ \\
\hline Secondary & 1.110 & 0.964 & 1.280 & 0.15 \\
\hline \multicolumn{5}{|l|}{ Child's age in month } \\
\hline 1-23 (Reference) & 1.00 & & & \\
\hline 24-35 & 0.901 & 0.820 & 0.990 & $0.03 * *$ \\
\hline $36-47$ & 0.635 & 0.576 & 0.700 & $0.00 * * *$ \\
\hline $48-59$ & 0.517 & 0.466 & 0.574 & $0.00 * * *$ \\
\hline \multicolumn{5}{|l|}{ Mother's age at birth } \\
\hline less than 20 (Reference) & 1.00 & & & \\
\hline 20-34 & 0.911 & 0.835 & 0.995 & $0.04 *$ \\
\hline \multicolumn{4}{|l|}{ Salt iodization test outcome } & 0.54 \\
\hline $\begin{array}{l}\text { Salt not tested or } 0 \text { PPM iodine } \\
\quad \text { (Reference) }\end{array}$ & 1.00 & & & \\
\hline between 0 to 15 PPM & 0.950 & 0.853 & 1.058 & 0.34 \\
\hline Above 15 PPM & 0.926 & 0.846 & 1.014 & $0.09 *$ \\
\hline \multicolumn{5}{|l|}{ Sex of household head } \\
\hline Female & 1.00 & & & \\
\hline Male & 1.058 & 0.922 & 1.216 & 0.43 \\
\hline \multicolumn{5}{|l|}{ Education level of household head } \\
\hline $\begin{array}{l}\text { Pre-primary or none or Don't } \\
\text { know (Reference) }\end{array}$ & 1.00 & & & \\
\hline Primary & 1.105 & 1.004 & 1.215 & $0.04 * *$ \\
\hline Secondary & 1.060 & 0.957 & 1.176 & 0.27 \\
\hline Higher Secondary or Higher & 0.976 & 0.841 & 1.132 & 0.75 \\
\hline \multicolumn{5}{|l|}{ Weight } \\
\hline Under weight (Reference) & 1.00 & & & \\
\hline Over Weight & 0.818 & 0.679 & 0.981 & $0.03^{* *}$ \\
\hline \multicolumn{5}{|l|}{ Materials used for handwash } \\
\hline Bar/Liquid soap/Detergent & 1.00 & & & \\
\hline No materials/ASH/Mud/Sand & 1.188 & 1.068 & 1.322 & $0.00 * * *$ \\
\hline \multicolumn{5}{|c|}{ Treat water to make it safer for drinking } \\
\hline Yes (Reference) & 1.00 & & & \\
\hline No & 1.071 & 0.930 & 1.232 & 0.34 \\
\hline Type of toilet & & & & \\
\hline not improved (Reference) & 1.00 & & & \\
\hline Improved & 0.880 & 0.790 & 0.980 & $0.02 * *$ \\
\hline Household Size & & & & \\
\hline more than 4 (Reference) & 1.00 & & & \\
\hline $1-4$ & 1.164 & 1.077 & 1.259 & $0.00 * * *$ \\
\hline Mother or primary caretaker's life & tisfaction in la & & & \\
\hline 1-6 (Reference) & 1.00 & & & \\
\hline $7-10$ & 0.862 & 0.794 & 0.936 & $0.00 * * *$ \\
\hline
\end{tabular}

cross-sectional study in India. ${ }^{11}$ This study also found that children of mothers who are satisfied with their lives are at less risk of developing childhood disease. Since the mothers who are satisfied with their life are concerned about their child's health, that may cause these symptoms. Incidence of childhood morbidity was also observed to vary with household wealth status. In several previous studies in Bangladesh (for instance, Kamal et al. (2015), ${ }^{5}$ Rayhan et al. (2007), ${ }^{9}$ and Rahman et al. $(2019)^{10}$ ) also find that the child of the rich households was at less risk of being exposed to morbidity than the child of poor households. by Banarjee et al. in India. ${ }^{31}$ also found that Children with small families are more likely to develop morbidity. This finding is coinciding with the findings of a study in Kenya. ${ }^{32}$

Among the various healthy behavior, it is found that improved toilet reduces the child morbidity risk, which is also exposed in the previous studies. ${ }^{10,33,34}$ This analysis also illustrates that salt with iodine and hygienic hand washing materials also reduces childhood morbidity. Samba et al. (2008) in their study in Indonesia found that utilizing adequate iodized salt reduces child malnutrition significantly. ${ }^{35}$ The result of a randomized control study in Pakistan ${ }^{36}$ showed that intensive handwashing practice reduces child morbidity by $47 \%$, which is also found previously by other studies. ${ }^{12,37,38}$ Though water treatment's impact on morbidity was found significant by other researchers, $3,22,39,40$ water treatment was found with an insignificant effect in present studies.

\section{Limitations}

While our results provide significant insights into the child morbidity of the determinant, they must be interpreted in light of certain limitations of the analysis. The majority of findings were focused on selfreport, which is vulnerable to prejudices and recollection of social desirability. There is some variance in this analysis, which may be due to greater inclusion in the model of this study of specific covariates compared to those found in previous studies. Another limitation of the study is that the AUC value is low, which indicates that we need to train our algorithm more.

\section{Funding}

This research did not receive any specific grant from funding agencies in the public, commercial, or not-for-profit sectors.

\section{Declaration of competing interest}

None.

\section{Acknowledgment}

A special thank goes to the United Nations Children's Fund (UNICEF) for enabling us to use Multiple Indicator Cluster Survey data from Bangladesh.

\section{References}

1 World Health Organization. Children: Reducing Mortality [Internet]. World Health Organization: WHO; 2018 [cited 2021 Apr 28]. Available from: https://www.who.in t/news-room/fact-sheets/detail/children-reducing-mortality.

2 Mahumud RA, Alam K, Renzaho AMN, et al. Changes in inequality of childhood morbidity in Bangladesh 1993-2014: a decomposition analysis. Joe W, editor. PloS One. 2019;14(6), e0218515.

3 Unicef. Bangladesh (BGD) - Demographics, Health \& Infant Mortality - UNICEF DATA [Internet]. UNICEF; 2015 [cited 2021 Apr 28]. Available from: https://data. unicef.org/country/bgd/.

4 Unicef. 140,000 Children in Bangladesh Could Die in the Next Decade unless More Is Done to Fight Pneumonia [Internet]. UNICEF; 2020 [cited 2021 Apr 28]. Available from: https://www.unicef.org/bangladesh/en/press-releases/140000-children-ban gladesh-could-die-next-decade-unless-more-done-fight-pneumonia.

5 Kamal MM, Hasan MM, Davey R. Determinants of childhood morbidity in Bangladesh: evidence from the demographic and health survey 2011. BMJ Open. 2015;5(10), e007538.

6 United Nations. The impact of COVID-19 on children [internet] [cited 2021 Jun 3]. Available from: https://unsdg.un.org/sites/default/files/2020-04/160420_Covid_Ch ildren_Policy_Brief.pdf; 2020.

7 Giashuddin MS, Kabir M, Hasan M. Economic disparity and child nutrition in Bangladesh. Indian J Pediatr. 2005;72(6):481-487.

8 United Nations. Goal 3 | department of economic and social affairs [Internet]. sdgs. un.org. 2020 [cited 2021 Jun 3]. Available from: https://sdgs.un.org/goals/goal3. 
9 Rayhan I, Khan MSH, Shahidullah. Impacts of bio-social factors on morbidity among children aged under-5 in Bangladesh. Asia Pac Popul J. 2007;22(1):65-75.

10 Rahman M, Hosen A, Khan MA. Association between maternal high-risk fertility behavior and childhood morbidity in Bangladesh: a nationally representative crosssectional survey. Am J Trop Med Hyg. 2019;101(4).

11 Raj A, Saggurti N, Winter M, et al. The effect of maternal child marriage on morbidity and mortality of children under 5 in India: cross-sectional study of a nationally representative sample. BMJ [Internet]. 2010;340:b4258, 8.

12 Hatt LE, Waters HR. Determinants of child morbidity in Latin America: a pooled analysis of interactions between parental education and economic status. Soc Sci Med. 2006;62(2):375-386.

13 El-Gilany AH, Hammad S. Epidemiology of diarrhoeal diseases among children under age 5 Years in dakahlia, Egypt. East Mediterr Health J. 2005;11(4):762-775.

14 Mitchell TM. Machine Learning. Singapore: Mcgraw-Hill; 1997.

15 Ayer T, Chhatwal J, Alagoz O, Kahn CE, Woods RW, Burnside ES. Comparison of logistic regression and artificial neural network models in breast cancer risk estimation. Radiographics. 2010;30(1):13-22.

16 Farran B, Channanath AM, Behbehani K, Thanaraj TA. Predictive models to assess risk of type 2 diabetes, hypertension, and comorbidity: machine-learning algorithms and validation using national health data from Kuwait-a cohort study. BMJ Open. 2013;3(5).

17 Aneja S, Lal S. Effective asthma disease prediction using naïve bayes -neural network fusion technique. In: 2014 International Conference on Parallel, Distributed and Grid Computing. 2014.

18 Salhi DE, Tari A, M-Tahar Kechadi. Using machine learning for heart disease prediction. Advances in Computing Systems and Applications. 2021:70-81.

19 Behroozi M, Sami A. A multiple-classifier framework for Parkinson's disease detection based on various vocal tests. International Journal of Telemedicine and Applications. 2016:1-9, 2016.

20 Islam M, Usman M, Mahmood A, Abbasi AA, Song O-Y. Predictive analytics framework for accurate estimation of child mortality rates for internet of things enabled smart healthcare systems. Int J Distributed Sens Netw. 2020;16(5), 155014772092889.

21 Siziya S, Muula AS, Rudatsikira E. Diarrhoea and acute respiratory infections prevalence and risk factors among under-five children in Iraq in 2000. Italian Journal of Pediatrics. 2009;35:8.

22 Kandala N-B, Emina JB, Nzita PDK, Cappuccio FP. Diarrhoea, acute respiratory infection, and fever among children in the democratic republic of Congo. Soc Sci Med. 2009;68(9):1728-1736.

23 National Institute of Population Research and Training (NIPORT), Mitra and Associates, ICF International. Bangladesh Demographic and Health Survey 2017-18. Dhaka, Bangladesh, and Rockville. Maryland, USA: NIPORT and ICF; 2020.

24 Bangladesh Bureau of Statistics (BBS), Unicef. Progotir Pathey, Bangladesh Multiple Indicator Cluster Survey 2019, Survey Findings Report. Bangladesh: Bangladesh Bureau of Statistics (BBS); 2019.
25 Hastie T, Tibshirani R, Friedman J. New York, NY. In: Springerlink (Online Service. The Elements of Statistical Learning: Data Mining, Inference, and Prediction. second ed. New York: Springer; 2009.

26 James G, Witten D, Hastie T, Tibshirani R. An Introduction to Statistical Learning: With Applications in R. Springer; 2013.

27 Gladstone BP, Muliyil JP, Jaffar S, et al. Infant morbidity in an Indian slum birth cohort. Arch Dis Child. 2008;93(6):479-484 [Internet].

28 Takele K, Zewotir T, Ndanguza D. Risk factors of morbidity among children under age five in Ethiopia. BMC Publ Health. 2019;19.

29 Hondru G, Wieringa FT, Poirot E, et al. The interaction between morbidity and nutritional status among children under five years old in Cambodia: a longitudinal study. Nutrients. 2019;11(7).

30 Ganguly E, Sharma PK, Bunker CH. Prevalence and risk factors of diarrhea morbidity among under-five children in India: a systematic review and meta-analysis. Indian $J$ Child Health. 2015;2(4):152-160.

31 Banerjee B, Hazra S, Bandyopadhyay D. Diarrhea management among under fives. Indian Pediatr. 2004;41(3):255-260.

32 Taffa N, Chepngeno G, Amuyunzu-Nyamongo M. Child morbidity and healthcare utilization in the slums of nairobi, Kenya. J Trop Pediatr. 2005;51(5):279-284.

33 Ndugwa RP, Zulu EM. Child morbidity and care-seeking in nairobi slum settlements: the role of environmental and socio-economic factors. J Child Health Care. 2008;12 (4):314-328

34 Ganguly E, Sharma PK, Bunker CH. Prevalence and risk factors of diarrhea morbidity among under-five children in India: a systematic review and meta-analysis. Indian $J$ Child Health. 2015;2(4):152-160.

35 Semba RD, de Pee S, Hess SY, Sun K, Sari M, Bloem MW. Child malnutrition and mortality among families not utilizing adequately iodized salt in Indonesia. The American Journal of Clinical Nutrition. 2008;87(2):438-444.

36 Luby SP, Agboatwalla M, Painter J, Altaf A, Billhimer WL, Hoekstra RM. Effect of intensive handwashing promotion on childhood diarrhea in high-risk communities in Pakistan: a randomized controlled trial. J Am Med Assoc. 2004;291(21):2547-2554.

37 Black R. Incidence and severity of rotavirus and Escherichia coli diarrhoea in rural Bangladesh implications for vaccine development. Lancet. 1981;317(8212):141-143.

38 Ram PK, DiVita MA, Khatun-e-Jannat K, et al. Impact of intensive handwashing promotion on secondary household influenza-like illness in rural Bangladesh: findings from a randomized controlled trial. PloS One. 2015;10(6).

39 Ezeh O, Agho K, Dibley M, Hall J, Page A. The impact of water and sanitation on childhood mortality in Nigeria: evidence from demographic and health surveys, 2003-2013. Int J Environ Res Publ Health. 2014;11(9):9256-9272.

40 Ferdous F, Das SK, Ahmed S, et al. Diarrhoea in slum children: observation from a large diarrhoeal disease hospital in dhaka, Bangladesh. Trop Med Int Health. 2014;19 (10):1170-1176. 